\title{
A importância do controle climático em museus
}

\author{
Kwok Chiu Cheung*
}

CHEUNG, K.C. A importância do controle climático em museus. Revista do Museu de Arqueologia e Etnologia, São Paulo, 18: 299-306, 2008.

Resumo: Entre os principais fatores climáticos que causam interferência nas coleções e devem ser controlados pelo sistema de climatização estão à temperatura, umidade absoluta, saturação e a condensação. Durante o monitoramento do acervo etnográfico exposto no Museu das Culturas Dom Bosco verificou-se a ocorrência de infestação causada por fungos. A presença desses organismos indicou que os artefatos estavam susceptíveis a danos permanentes e de difícil restauração, devido à rápida taxa de reprodução desses organismos em condições favoráveis e ao modo pelo qual utilizam o substrato para alimentação. Desse modo, a equipe administrativa, junto à equipe técnica, decidiu antecipar a instalação do sistema de climatização do salão de exposição permanente. Além da instalação dos climatizadores foram estabelecidas várias medidas associadas ao controle e manutenção da temperatura e umidade estabelecidas.

Palavras-chave: Conservação - Higienização - Infestação biológica - Fungos.

\section{Introdução}

s modificações físicas ou químicas causadas por flutuações climáticas intensas afetam o material que compõe os artefatos (Maekawa \& Toledo 2001). A umidificação, o dessecamento, a dilatação ou retração, assim como a luminosidade excessiva são processos que provocam modificações temporárias, mas que podem causar danos irreversíveis ao material.

O clima dentro de um edifício é diretamente influenciado pelo ambiente externo. Para Toledo (2003) o edifício pode contribuir para

${ }^{*}$ ) Departamento de Conservação e Pesquisa do Museu das Culturas Dom Bosco - MCDB. Universidade Católica Dom Bosco - UCDB. cheung@ucdb.br acelerar o processo de degradação das obras ou pode ajudar a suavizar, ou reter, o processo de envelhecimento da coleção que está ali abrigada. Em uma edificação podemos identificar que alguns setores são mais frios que outros ou que os ambientes nos andares inferiores são mais úmidos em relação aos superiores. Isso ocorre porque cada zona dentro de um prédio tem seu próprio comportamento climático. Alguns ambientes podem reagir da mesma forma às variações climáticas externas, enquanto outros podem ter variações individuais de acordo com sua localização dentro do prédio (Padfield 1990; Energy Estrategies Comittee 2005).

De acordo com Padfield \& Larsen (2002), para se estabilizar o clima interno, as construções devem possuir barreiras como: isolamento em telhados para redução do efeito do calor da radiação solar, isolamento das paredes para 
proteção da chuva e do ar úmido, redução do número de aberturas para diminuir a troca de ar, entre outros.

Dependendo da inércia higrotérmica e da capacidade de isolamento do prédio as variações climáticas externas serão menos sentidas internamente. A inércia térmica de uma construção é sua capacidade de resistência às variações extremas de temperatura, ocorridas no ambiente externo. Inércia higrotérmica é um conceito equivalente, quando consideradas as variações de umidade relativa (Diniz 2006).

Um edifício pode atuar como agente passivo de conservação, ou seja, quando cria condições adequadas à manutenção do acervo, quando promove um ambiente seco e estável (Toledo 2003). Nesse contexto, o edifício do museu pode suavizar, ou agravar, as condições climáticas externas. Este funciona como um envelope, como um escudo, é a primeira barreira de proteção da coleção (Maekawa \& Toledo 2001). Mas se este não for pensado e construído de maneira adequada, poderá piorar tais condições externas.

Mesmo que muitos prédios sejam especialmente construídos para abrigar coleções e museus, é muito importante monitorar a relação existente entre os climas interno e externo. Desse modo, é importantíssimo ter uma boa compreensão do comportamento climático de um prédio que abriga coleções (Suarez \& Tsutsui 2004). Para identificação e detalhamento das características climáticas internas de uma edificação é necessário um estudo climático preliminar. Segundo Diniz (2006), um estudo climático deve permitir:

- Reconhecer em qual extensão as condições internas do prédio são afetadas pelo clima externo;

- Selecionar as áreas mais adequadas para abrigar as coleções;

- Colocar as coleções mais sensíveis nos locais mais estáveis;

- Indicar se uma vitrine está montada adequadamente;

- Proporcionar uma base sólida para propor a estabilização, umidificação ou desumidificação de um ou mais setores durante certos períodos do ano;
- Julgar quando é o melhor momento de montar uma exposição temporária, a fim de evitar mudanças climáticas abruptas, que podem colocar em risco a coleção.

\section{Características ideais da climatização em museus}

De um modo geral, os museus possuem coleções muito sensíveis a diversos fatores, sejam biológicos ou climáticos. Desse modo, o controle desses fatores atua como regulador das condições micro-climáticas, diminuindo as variações e impedindo o aparecimento de infestações por fungos ou insetos.

O controle climático em edificações destinadas a abrigar coleções difere dos demais sistemas de condicionadores de ar devido a diversos fatores. Dentre eles podemos destacar:

- A climatização visa primordialmente à manutenção e conservação das coleções, considerando os tipos de materiais que compõem os artefatos e sua resposta às mudanças climáticas;

- Deve controlar, além da temperatura, a taxa de umidade relativa do ar nos diferentes ambientes da edificação;

- Deve manter a temperatura e a umidade interna em valores estáveis ou com flutuações mínimas entre valores previamente estabelecidos;

- Deve permanecer ligado durante 24 horas e em tempo integral (inclusive nos dias em que o museu estiver fechado), considerando que determinados objetos não podem sofrer grandes variações de temperatura e umidade devido a sua capacidade de dilatação e retração, ou ganho e perda de umidade;

- Mesmo propiciando um ambiente confortável ao visitante, o público é considerado um elemento interferente na estabilidade do clima interno de um museu, isso porque a respiração humana aumenta a umidade do ar e a temperatura. Assim, grupos muito grandes podem 
alterar as condições micro-climáticas de um determinado setor durante a sua visita.

Outros fatores que também causam interferência nas coleções e devem ser controlados pelo sistema de climatização são umidade absoluta, saturação e a condensação. Entretanto, podemos sintetizar em basicamente dois grandes níveis os processos conservativos em um museu:

- O controle da temperatura é fundamental para conservação preventiva de um acervo, pois níveis elevados de calor contribuem sensivelmente para a desintegração dos materiais. $\mathrm{O}$ calor excessivo acelera a velocidade da maioria das reações químicas, inclusive a deterioração, que é dobrada a cada aumento de $10^{\circ} \mathrm{C}$ (Ackery et al. 2002).

- Os altos níveis de umidade fornecem o meio necessário para promover as reações químicas prejudiciais aos materiais e, combinados com a alta temperatura, favorecem a proliferação de fungos e a atividade de insetos.

\section{Estudo de caso:}

\section{A dinâmica da infestação e o processo de} climatização do Museu das Culturas Dom Bosco

As novas instalações do Museu das Culturas Dom Bosco foram inauguradas oficialmente no dia 30 de novembro de 2006 dentro do Parque das Nações Indígenas, em Campo Grande, Mato Grosso do Sul. A inauguração dá início a uma nova fase do Museu que agora está situado em uma região nobre da cidade, dispondo de maior área física, apresentando novo espaço expositivo e, principalmente, apresentando novas tendências e conceitos museais.

Entretanto, é importante destacar que se tratou de uma inauguração parcial, pois parte das instalações ainda estão em fase de construção. Mesmo assim, o salão de exposição permanente, que estava completamente montado expondo objetos referentes à Arqueologia e Etnologia do Brasil, foi apresentado com sucesso ao público presente. Após a inauguração o
Museu das Culturas Dom Bosco permaneceu aberto até o mês de fevereiro de 2007, quando foi fechado devido à continuidade do processo de montagem dos expositores e adequação do edifício aos padrões museológicos.

Durante esse período de fechamento foram avaliados os materiais utilizados na construção e montagem das vitrines, bem como o acabamento feito pela equipe executora. Para essa avaliação foram considerados todos os padrões e técnicas internacionais de museologia, assim como padrões de estética e execução do projeto. Além disso, foi feita uma avaliação do ambiente interno do salão de exposição permanente e de como os objetos expostos estavam respondendo a possíveis variações de temperatura e umidade.

\section{Monitoramento da coleção etnográfica}

Após monitoramento e vistoria do acervo etnográfico exposto no Museu das Culturas Dom Bosco verificou-se a ocorrência de infestação causada por fungos, sendo que o grau de desenvolvimento desses microrganismos variou de acordo com a composição dos próprios artefatos. Os objetos compostos basicamente por celulose (madeira, palha, folhagem) apresentaram maior suscetibilidade a este tipo de infestação, embora as cerâmicas também estejam sujeitas à ação de fungos.

Assim, os objetos de madeira apresentavam estágios avançados de infestação e, muitos deles, com estruturas reprodutivas (hifas e esporos) cobrindo toda a sua superfície. Nos artefatos de madeira da coleção Karajá (Fig. 1) podia-se facilmente observar a formação de diversas colônias (bolor). Algumas cerâmicas da coleção Bororo também apresentavam grandes infestações e formação de corpo reprodutivo, sendo que nos demais artefatos de madeira e plumária foram observadas fases iniciais de infestação (Figs. 2 e 3).

\section{Características da infestação por fungos}

A presença de fungos indicou que os artefatos estavam susceptiveis a danos permanentes e de difícil restauração, devido à rápida taxa de reprodução desses organismos em condições 

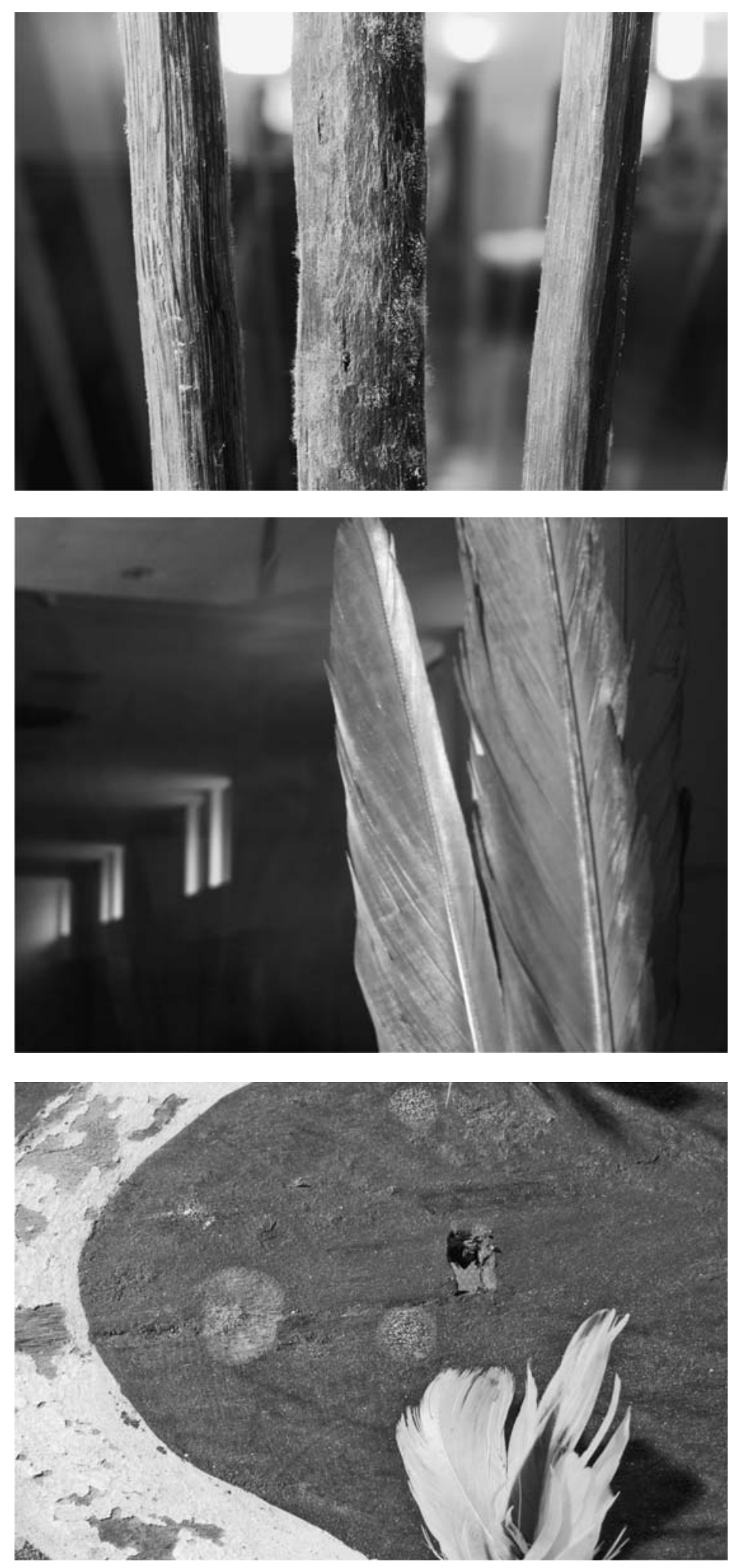

Fig. 1. Lanças Karajá apresentando infestação por fungos no salão de exposição.

Fig. 2. Plumária dos arcos Bororo apresentando infestação por fungos no salão de exposição permanente do Museu das Culturas Dom Bosco, Campo Grande, MS.

Fig. 3. Artefato Bororo apresentando infestação por fungos no salão de exposição permanente do Museu das Culturas Dom Bosco, Campo Grande, MS. 
favoráveis e ao modo pelo qual utilizam o substrato para alimentação. Os fungos em geral se alimentam por absorção, formam uma camada celular (biofilme) sobre determinados substratos (principalmente matéria orgânica) que retém a umidade do ar e acelera o processo de decomposição. Além disso, produzem exoenzimas similares às enzimas digestivas animais que são responsáveis pela degradação do substrato.

De um modo geral, os fungos possuem ciclo biológico variando entre 7 e 15 dias e utilizam uma variedade de substratos alimentares. Devido ao modo pelo qual se desenvolvem, degradando estruturas orgânicas, estão classificados em dois tipos: decompositores e parasitas. Os decompositores são aqueles capazes de degradar matéria orgânica morta, fragmentando-as em pequenas partes e tornando possível sua reutilização por outros organismos. Os fungos considerados parasitas sobrevivem à custa de organismos vivos e são agentes patógenos de plantas e animais, inclusive do homem.

A infestação encontrada no acervo do Museu das Culturas Dom Bosco foi causada por fungos decompositores, possivelmente do grupo Zygomiceta que formam tecidos filamentosos sobre o substrato utilizado como alimento. Devido a isso, foi necessário o tratamento urgente do acervo infestado, pois, além dos danos causados aos objetos, existem muitos grupos extremamente oportunistas e patógenos, que poderiam acarretar infecções respiratórias nos funcionários que manuseiam as peças e mesmo em visitantes do museu, principalmente indivíduos alérgicos.

É importante destacar que não existem ambientes livres da presença de fungos, pois se reproduzem por esporos microscópicos que são lançados no ar e se disseminam com enorme facilidade. Entretanto, esses microrganismos somente se desenvolvem quando encontram condições favoráveis, ou seja, basicamente altas temperaturas e umidade relativa do ar elevada. A ausência de luminosidade solar aumenta consideravelmente a velocidade da infestação, por tornar ainda mais propício às condições microclimáticas. Contudo, o controle efetivo dos fatores que favorecem tal proliferação é a única forma de proteger os acervos que envolvem materiais orgânicos.

Desse modo, pode-se afirmar que os dois principais fatores que favoreceram a infestação das coleções foram altas temperaturas e umidade elevada. A elevada umidade do ar é explicada pelas características do ambiente externo, uma vez que as instalações estão próximas ao curso do córrego Prosa, situada no declive do terreno em direção ao mesmo, somando ainda a proximidade de uma área florestada (Parque Estadual do Prosa). A alta temperatura é reflexo do clima da região Centro-Oeste, médias de $35^{\circ} \mathrm{C}$, e dentro das instalações o problema se acentuou devido à ausência de sistemas de condicionamento de ar, aliada à baixa ventilação e pouca iluminação natural.

Outro fator importante foi o período chuvoso (novembro a março), principal responsável pela elevada umidade nesse período do ano e, do mesmo modo níveis de umidade extremamente baixos nos meses de estiagem (abril a outubro). A umidade relativa em níveis muito baixos que, costuma ocorrer no inverno, pode levar ao ressecamento e aumento da fragilidade de certos materiais. Essas flutuações de temperatura e umidade relativa do ar são também extremamente danosas. Muitos objetos reagem às mudanças sazonais, absorvendo e liberando umidade, ou contraindo-se e expandindo-se, sendo que estas alterações podem acarretar danos permanentes.

\section{Medidas de conservação e restauro das peças} infestadas

Após a identificação da infestação os objetos foram retirados dos expositores para análise do grau de infestação e aplicação do melhor método de higienização. O nível de infestação variou de acordo com a composição dos objetos, sendo que aqueles feitos de madeira apresentaram maior susceptibilidade, quando comparados com outros tipos de material (cerâmica e penas).

Os procedimentos de higienização foram aplicados de acordo com dois principais fatores: grau de infestação e de fragilidade de cada objeto. O grau de infestação foi diferente entre 
os diferentes setores do salão de exposição temporária, indicando também diferenças na distribuição da umidade relativa. É importante destacar que o Museu das Culturas Dom Bosco apresentou uma nova forma de expor suas coleções, novos conceitos e técnicas. Os expositores localizam-se no chão, sob os pés dos visitantes que caminham sobre vidros duplos e resistentes a $500 \mathrm{Kg}$ de peso. Todos os expositores foram impermeabilizados com uma camada de manta asfáltica de aproximadamente $1 \mathrm{~cm}$ de espessura, revestida com duas camadas de concreto. Esses procedimentos visam a impedir que a umidade venha do solo.

A composição dos objetos infestados variou entre celulose (madeira, bambu, folhas de palmeira, algodão), queratina (penas, pêlos e couro) e argila (cerâmica e vasos). As peças de madeira apresentaram maior susceptibilidade à infestação, isso porque a celulose pode ser facilmente degradada em condições de altos níveis de umidade e temperatura, além disso, outro fator importante a ser considerado como um facilitador foi a idade desses objetos (média de 50 anos de coleta).

De um modo geral, toda a superfície dos objetos infestados foi inicialmente aspirada com um aparelho aspirador de pó apropriado ao trabalho em museus, aqueles que continham plumária foram cobertos com tule para evitar danos durante a higienização. Os objetos com pinturas e resinas também receberam o mesmo cuidado para evitar alterações na coloração e estrutura do objeto. Após serem aspiradas, utilizaram-se trinchas para higienização e papel toalha.

Este tipo de infestação causada por fungos merece atenção diferenciada devido ao desenvolvimento desses organismos ocorrer inicialmente dentro dos objetos, tornando-se visíveis somente quando já estão formando estruturas reprodutivas (esporulando). Desse modo, é importante tratar internamente os objetos com produtos adequados para evitar re-infestações. Entretanto, deve-se ter extremo cuidado e analisar muito bem qual o produto a ser utilizado, qual a melhor forma de aplicação, qual o tipo de solvente e, indispensável para segurança de quem manuseia os objetos, qual o poder toxicológico. A consideração desses fatores é de essencial importância para a manutenção das características originais do objeto, e para a saúde da equipe de um museu.

Assim, para finalizar o processo de higienização dos objetos infestados foram aplicados diferentes produtos, de acordo com a composição e o nível de infestação sofrida. Objetos compostos de madeira e sem pintura, adornos, plumária ou quaisquer ornamentos foram tratados com tribromofenol e cipermetrina na forma de aspersão direta. Os objetos que possuíam penas, pinturas naturais ou características que poderiam ser perdidas devido ao solvente foram hermeticamente acondicionados em sacos plásticos especiais juntamente com absorvedores de oxigênio (anoxia).

\section{O processo de climatização do Museu das Culturas Dom Bosco}

Após a constatação dos problemas com o ambiente interno do Museu das Culturas Dom Bosco, a equipe administrativa, junto à equipe técnica, decidiu antecipar a instalação do sistema de climatização do salão de exposição permanente. A climatização do Museu envolveu a instalação de controladores climáticos adequados e sua operação no sentido de manter condições estáveis, bem como padrões de conservação préestabelecidos.

De acordo com as especificações técnicas obtidas com a equipe executora, instalou-se um sistema de ar condicionado do tipo expansão direta (multisplit), dotado de compressores tipo scroll com condensador remoto arrefecido a ar. Para aferir o controle da temperatura e umidade foi instalado um controlador Thermidstat. A distribuição de ar no salão foi feita através de dutos construídos em chapa de aço galvanizado com medidas estabelecidas pela ABNT-NBR- 6401.

Para tomada de ar externa foram construídas seis casas de máquinas que possuem entradas de ar fabricadas em alumínio anodizado, na cor natural, dotadas de telas metálicas, registro de ar para regulagem da quantidade de ar exterior e filtro de ar permanente e lavável. Todo o sistema recebeu isolamento termoacústico para evitar os efeitos do calor externo e, ruídos ou vibrações excessivas. 
O processo de umidificação e desumidificação foi pré-estabelecido dentro de um setpoint entre 40 e $50 \%$ de umidade relativa, assim quando os valores decrescem ou aumentam e atingem niveis que não estão dentro desta faixa de variação, o Thermidstat responde através da ativação da saída ou entrada de umidade. De um modo geral, existem vários modos para umidificar e desumidificar um ambiente, o sistema adotado no Museu das Culturas Dom Bosco utiliza a umidificação com ventilador e o resfriamento para desumidificar.

Para climatização total do salão de exposição permanente que possui $960 \mathrm{~m}^{2}$ foram instalados seis módulos ventiladores de 7,5 TR 40MSC 090236V, seis módulos ventiladores de 7,5 TR 40MSC090 TRF, e para controle da entrada de ar seis grelhas modelo VDF-711 397 x 397 e seis grelhas AGS-A 625 x 1225 .

A programação pré-definida do sistema de climatização obedece aos seguintes valores:

- Temperatura: estável em $25^{\circ}$ Celsius

- Umidade Relativa do Ar: mínima de $40 \%$ e máxima de $50 \%$

- Horário de funcionamento: integral (24 horas por dia), todos os dias inclusive sábados, domingos e feriados.

Além da instalação dos climatizadores foram estabelecidas várias medidas associadas ao controle e manutenção da temperatura e umidade estabelecidas. Entre essas medidas podem-se destacar:

- Diminuição das aberturas de ventilação e exclusão total do sistema de ventilação forçada;

- Monitoramento climático do ambiente expositivo e das vitrines através de termo-higrômetros digitais portáteis;
- Acompanhamento das variações higro-térmicas externas para efeito comparativo;

- Realização de monitoria e vistoria técnica diariamente dos objetos expostos e acondicionados em todos os setores do Museu.

\section{Considerações Finais}

Dentro de uma edificação destinada a abrigar um museu, o sistema de climatização representa um elemento indispensável, seja para atender aos padrões estéticos ou museológicos e conservativos. O Museu das Culturas Dom Bosco figura como a principal instituição ligada à preservação da cultura material, a educação patrimonial e ambiental em Mato Grosso do Sul. O Museu possui coleções extremamente sensivveis às variações ambientais devido à estrutura dos artefatos e sua susceptibilidade aos agentes físicos e químicos do clima.

Devido a isso, um sistema de climatização deve obedecer a diversos critérios previamente estabelecidos que visem primordialmente à conservação e manutenção das coleções pelo maior tempo possivel. Deve controlar as condições micro-climáticas, para que não ocorram situações propícias ao desenvolvimento de fungos, proliferação de insetos ou outros organismos que possam acelerar o processo de degradação dos objetos.

Apoio: 
CHEUNG, K.C. The importance of the climatic control in museums. Revista do Museu de Arqueologia e Etnologia, São Paulo, 18: 299-306, 2008.

\begin{abstract}
Among the principal climatic factors that cause interferences in the collections and have to be controlled by the climatization system are the temperature, absolute humidity, saturation and condensation. Throughout tracking of the exposed etnographic collection at the Museum of the Cultures Don Bosco it was verified the occurrence of infestation by fungi. The presence of these organisms has indicated that the artifacts were susceptible to permanent damages and of difficult restoration, because of the fast rate of reproduction of these organisms in favorable conditions and the way that they use the substract for feeding. In this way, the administrative team joined to the technical team decided to anticipate the installation of the climatization system of the permanent exposition hall. Besides the installation of climatizators, many measures were established together with the control and maintenance of the established temperature and humidity.
\end{abstract}

Key-words: Conservation - Biological infestation - Fungi.

\title{
Referências bibliográficas
}

ACKERY, P.R., DOYLE, A.; PINNIGER, D.B.

2002 Safe high temperature pest eradication is the answer in the bag? Biology Curator, 22: $13-14$.

DINIZ, V.

2006 Curso: Conservação de Acervos. Módulo: Edifícios que abrigam soluções. Curitiba.

\section{ENERGY ESTRATEGIES COMITTEE}

2005 National appliance and energy efficiency comitee under the auspices of the Australian

MAEKAWA, S.; TOLEDO, F. and New Zealand Ministerial council for energy.

2001 Sustainable climate control for historic buildings in hot and humid regions. The 18th Conference on Passive and Low Energy PADFIELD, $\mathrm{T}$. Architecture, Florianópolis, Brazil.

1990 Low-Energy Climate Control in Museum
Stores. In: Prepints, 9th. Triennial Meeting, ICOM Committee for Conservation II, Paris: 596-601.

PADFIELD, T.; LARSEN, P.K.

2002 Semi-passive air conditioning of an archive. In: Conservation Department. The National Museum of Denmark, Brede. DK-2800 Kgs. Lyngby, Denmark: 1-6.

SUAREZ, A.; TSUTSUI, N.

2004 The value of museum collections for research and society. Bioscence, 54 (1): 66-74.

TOLEDO, F.

2003 O controle climático em museus quentes e úmidos conservação preventiva e o controle climático. Acessado em: 08/11/2007. In: http://www.museuvictormeirelles.org.br/ agenda/2003/seminario/franciza_toledo.htm 